\title{
ATIVIDADE RESIDUAL E CARÊNCIA IRREGULAR DO ÁCIDO DICLOROFENOXIACÉTICO (2,4-D) NO DESENVOLVIMENTO INICIAL DA SOJA
}

\author{
Gustavo Cândido Cecato ${ }^{1}$ \\ André Vasquez Souza ${ }^{1}$ \\ Franciele da Silva Quemel ${ }^{2}$ \\ Juliana Silveira do Valle ${ }^{3}$ \\ Simone de Melo Santana Gomes ${ }^{3}$ \\ Ana Daniela Lopes ${ }^{3}$
}

CECATO, G. C.; SOUZA, A. V.; QUEMEL, F. da S.; VAllE, J. S. do; GOMES, S. de M. S.; LOPES, A. D. Atividade residual e carência irregular do ácido diclorofenoxiacético $(2,4 \mathrm{D})$ no desenvolvimento inicial da soja. Arq. Ciênc. Vet. Zool. UNIPAR, Umuarama, v. 20, n. 3, p. 167-171, jul./set. 2017.

RESUMO: O 2,4-D (ácido diclorofenoxiacético) é amplamente utilizado no controle seletivo, pós-emergência, de plantas de folha estreita, como trigo, milho, arroz, entre outras. Contudo seu uso indiscriminado pode ocasionar problemas no desenvolvimento da cultura. O objetivo do trabalho foi avaliar os danos causados pelo uso inadequado do 2,4-D no desenvolvimento inicial da soja (Glycine max). Os tratamentos consistiram na combinação de cinco períodos de carência: um, quatro, oito, 12 e 15 dias antes da semeadura da soja e duas doses de aplicação: a dose recomendada e a dose duplicada (L/ha), consistindo em um esquema fatorial $5 \times 2$ com três repetições. As plantas foram cultivadas por 44 dias, e em seguida coletadas e analisadas quanto à taxa de germinação (\%), número de rebrota, índice de clorofila, comprimento de raiz e parte aérea $(\mathrm{cm})$, massa seca e fresca (g). A dose duplicada revelou maior efeito sobre todas as variáveis analisadas, reduzindo em $20 \%$ a porcentagem de emergência. $\mathrm{O}$ índice de clorofila decresceu quando comparados o menor período de carência (um dia) e o maior (15 dias), e na dose duplicada. A massa seca também foi superior na dose recomendada, assim como o comprimento da raiz e da parte aérea. Os períodos de carência de um, quatro e oito dias foram os que mais influenciaram o crescimento da raiz.

PALAVRAS-CHAVE: Dessecação. Glycine max. Herbicida.

\section{RESIDUAL ACTIVITY AND IRREGULAR DEPLETION OF DICHLOROPHENOXYACTIC ACID $(2,4-D)$ IN THE EARLY DEVELOPMENT OF SOYBEAN}

\begin{abstract}
Dichlorophenoxyacetic acid (2,4-D) is widely used in the selective, post-emergence control of narrow-leaf plants such as wheat, corn, and rice, among others. However, its uncontrolled use can cause problems in the development of the crop. The purpose of this paper was to evaluate the damage caused by the inadequate use of 2,4-D in the early development of soybean (Glycine max). The treatments consisted of a combination of five grace periods: 1, 4, 8, 12 and 15 days before sowing; and two application doses: the recommended dose and a duplicate dose (L/ha), consisting of a factorial matrix of $5 \times 2$, with three replicates. The plants were cultivated for 44 days, then collected and analyzed for germination rate $(\%)$, regrowth number, chlorophyll index, root and shoot length $(\mathrm{cm})$, dry and fresh mass $(\mathrm{g})$. The duplicate dose showed a greater effect on all analyzed variables, reducing the emergency percentage by $20 \%$. The chlorophyll index decreased when compared to the shortest (1 day) and longest (15 days) grace periods, and in the duplicate dose. Dry mass was also higher when using the recommended dose, as well as the root and shoot length. Grace periods of 1, 4 and 8 days were the ones that were most influenced the root growth.
\end{abstract}

KEYWORDS: Dissecation. Glycine max. Herbicide.

\section{ACTIVIDAD RESIDUAL Y CARENCIA IRREGULAR DEL ÁCIDO DICLOROFENOXIACÉTICO (2,4-D) EN EL DESARROLLO INICIAL DE LA SOJA}

RESUMEN: El 2,4-D (ácido diclorofenoxiacético) es ampliamente utilizado en el control selectivo, pos emergencia, de plantas de hoja estrecha, como trigo, maíz, arroz, entre otras. Sin embargo, su uso indiscriminado puede ocasionar problemas en el desarrollo de la cultura. El objetivo del trabajo fue evaluar los daños causados por el uso inadecuado del 2,4-D en el desarrollo inicial de la soja (Glycine max). Los tratamientos consistieron en la combinación de cinco períodos de carencia: 1, 4, 8, 12 y 15 días antes de la siembra de la soja y dos dosis de aplicación: la dosis recomendada y la dosis duplicada (L/ha), consistente en un esquema factorial $5 \times 2$ con tres repeticiones. Las plantas fueron cultivadas por 44 días, y luego recolectadas y analizadas en cuanto a la tasa de germinación (\%), número de rebrote, índice de clorofila, longitud de raíz y parte aérea $(\mathrm{cm})$, masa seca y fresca (g). La dosis duplicada reveló un mayor efecto sobre todas las variables analizadas, reduciendo en un $20 \%$ el porcentaje de emergencia. El índice de clorofila disminuyó cuando se comparó el menor período de carencia (1 día) y el mayor (15

DOI: 10.25110 /arqvet.v20i3.2017.6694

${ }^{1}$ Acadêmico do curso de Graduação em engenharia agronômica pela Universidade Paranaense - UNIPAR.

${ }^{2}$ Mestranda em Biotecnologia aplicada à agricultura pela UNIPAR

${ }^{3}$ Docentes do Programa de Pós-graduação em Biotecnologia Aplicada à Agricultura da UNIPAR. Umuarama - PR. E-mail: anadanielalopes@prof.unipar.br 
días), y en la dosis duplicada. La masa seca también fue superior en la dosis recomendada, así como la longitud de la raíz y de la parte aérea. Los períodos de carencia de 1, 4 y 8 días fueron los que más influenciaron el crecimiento de la raíz.

PALABRAS CLAVE: Desecación. Glycine Max. Herbicida.

\section{Introdução}

O manejo de plantas daninhas é uma prática indispensável para a maioria das culturas de importância econômica, sendo a aplicação de herbicidas uma das alternativas de maior eficiência para seu controle. Tanto no cultivo convencional como no plantio direto, a ação das plantas invasoras é bem conhecida, e sua presença causa danos devido à competição por água, luz, nutriente e espaço, fatores que comprometem o desenvolvimento da cultura e, consequentemente, a sua produção (SILVA et al., 2011). O controle químico de plantas daninhas aumentou sobremaneira especialmente em função da expansão da fronteira agrícola (ALVES, 1999) e vem crescendo com o aumento da área destinada ao plantio direto (PURÍSSIMO, 1999).

Dentre os herbicidas que vêm sendo aplicados, seja em dessecação para o plantio direto ou mesmo no controle direto das plantas daninhas, destaca-se o 2,4-D (ácido 2,4-diclorofenoxiacético), uma auxina endógena sintética, amplamente utilizada na agricultura. Este herbicida é derivado do ácido fenoxiacético, e quando em contato com a folha, movimenta-se por meio dos espaços intracelulares até atingir o floema. Em seguida, dirige-se para as regiões meristemáticas apicais e radiculares e em contato com a raiz segue a rota da transpiração por meio do xilema dirigindo-se para as partes aéreas da planta (GAZZIERO; NEUMAIER, 1985; BRIDGES, 2003).

A soja é uma dicotiledônea e o uso do 2,4-D nessa cultura restringe-se ao pré-plantio, operação comumente chamada de dessecação, na qual se aplica o herbicida a fim de eliminar qualquer erva daninha que venha competir com ela. O herbicida possui uma persistência de solo relativamente curta, não superior a 30 dias em solos argilosos e clima quente, quando aplicado em dosagens comerciais (SILVA; SILVA, 2007).

Segundo recomendações técnicas (ADAMA BRASIL S/A ${ }^{\circledR}, 2017$ ) a carência entre a dessecação e o plantio deve ser de no mínimo 15 dias. Entretanto, o efeito de sobreposição de dose é frequentemente observado durante as aplicações. Isto ocorre geralmente nas entrelinhas de aplicação, áreas de manobras, em função da má regulagem do equipamento de pulverização, deriva eólica entre outros (MAGALHÃES et al., 1997). Esta sobreposição, que representa uma duplicação da dose recomendada, pode afetar o crescimento, desenvolvimento e produtividade da cultura.

Diante disso, este trabalho teve por objetivo avaliar os efeitos fitotóxicos do 2,4-D, sobre a emergência de plântulas e desenvolvimento inicial da soja quando submetida a diferentes períodos de carência, sob a simulação do efeito de duplicação da dose aplicada.

\section{Material e Métodos}

O experimento foi conduzido entre os meses de junho e agosto de 2017 na casa de vegetação da Universidade Paranaense - Campus 3, Umuarama-PR.

Inicialmente, sementes de $C$. spectabilis foram se- meadas em vasos com capacidade para 1,5 litros preenchidos com solo do tipo Argissolo Vermelho distrófico $(\mathrm{V}<50 \%)$, coletado no município de Umuarama - PR. A adubação foi realizada utilizando 4-14-08, na proporção de $1 \mathrm{~g}$ por vaso e calcário dolomítico na proporção de $0,9 \mathrm{~g}$ por vaso. Após 15 dias da semeadura as plântulas foram submetidas à aplicação do herbicida comercial AMINOL $806^{\circledR 11}$ a base de ácido diclorofenoxiacético (concentrado solúvel $670 \mathrm{~g} / \mathrm{L}$ ).

O volume de água recomendado para aplicação do produto varia entre 180 e 360 L/ha (RODRIGUES; ALMEIDA, 2011). Neste experimento, portanto, foram utilizados $180 \mathrm{~L} / \mathrm{ha}$, o equivalente a $18 \mathrm{~mL} / \mathrm{m}^{2}$ com base na área do vaso $\left(0,0283 \mathrm{~m}^{2}\right)$. Os tratamentos consistiram na aplicação de duas doses do produto, as quais foram denominadas dose recomendada, aquela preparada conforme orientação do fabricante, e dose duplicada, representada pela reaplicação da dose simples a fim de simular o efeito de sobreposição. A semeadura foi realizada em diferentes períodos de carência (um, quatro, oito, 12 e 15 dias). O delineamento experimental adotado foi inteiramente casualizado, em esquema fatorial $5 \times 2$ totalizando dez tratamentos com três repetições.

Após a aplicação do herbicida para dessecação das plântulas de $C$. spectabilis e avaliação do efeito residual sobre a germinação e desenvolvimento inicial de soja, sementes de soja (Nideria, cultivar 5909rr) inoculadas com Bradyrhizobium, foram semeadas de acordo com os intervalos de carência pré-estabelecidos (um, quatro, oito, 12 e 15 dias). Aos 44 dias após a semeadura, as plantas foram coletadas e estimou-se: o percentual de plântulas emergidas e a porcentagem de rebrota de $C$. spectabilis, o índice de clorofila, a massa fresca e seca (g) e o comprimento da parte aérea e raiz (cm). Para a avaliação do percentual de plantas emergidas procedeu-se a contagem de plântulas presentes em cada vaso. Em cada vaso foram semeadas cinco sementes, totalizando quinze sementes por tratamento.

O índice de clorofila foi medido a partir da terceira folha de cada planta com o auxílio de um clorofilômetro digital - Clorofi LOG, modelo CFL 1030 (Falker®). Para a determinação da massa fresca foi utilizada uma balança de precisão com sensibilidade de $1 \mathrm{~g}$. Após a obtenção da massa fresca, as plantas foram mantidas em estufa regulada a $60{ }^{\circ} \mathrm{C}$ até atingir massa constante. $\mathrm{O}$ comprimento da parte aérea e raiz foram mensurados por meio de uma régua graduada.

Todas as análises foram realizadas em triplicata. Os dados foram submetidos à análise de variância a 5\% de significância e quando constatado efeito significativo, as médias foram comparadas pelo teste de Tukey $(\alpha=0,05)$, utilizando o programa estatístico Sisvar (FERREIRA, 2011).

\section{Resultados}

O número de plantas de soja emergidas variou estatisticamente entre os tratamentos avaliados (Figura 1) indicando redução significativa nos tratamentos submetidos à dosagem duplicada de 2,4-D. A porcentagem de emergência

${ }^{1}$ AMINOL $806^{\circledR}$, Cooperativa Agroindustrial Consolata - COPACOL, Formosa do Oeste - PR. 
variou de 66,66 a $86,66 \%$ para as doses avaliadas evidenciando que o comportamento germinativo foi influenciado apenas pelas doses.

Figura 1: Percentual de emergência das plântulas de soja expostas a diferentes doses de 2,4-D em pré-emergência. Significativo ao nível de $5 \%$ de probabilidade.

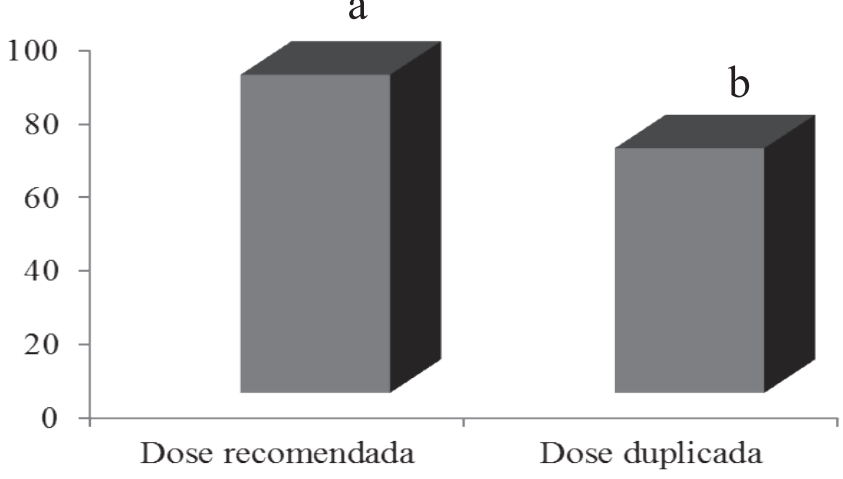

O número de rebrotas de $C$. spectabilis foi superior nos tratamentos que receberam a dose recomendada (Figura 2) quando comparado àqueles com dose duplicada (Figura 3), o que evidencia a dificuldade de controlar plantas daninhas. Contudo, a prática de aplicar o herbicida em desacordo com a dose recomendada, compromete, conforme observado, a taxa de emergência e o desenvolvimento gerando plantas com parte aérea e sistema radicular deficientes (Figura 1 e Tabela 2).

Figura 2: Número de rebrota de $C$. spectabilis após aplicação de 2,4-D na dose recomendada.

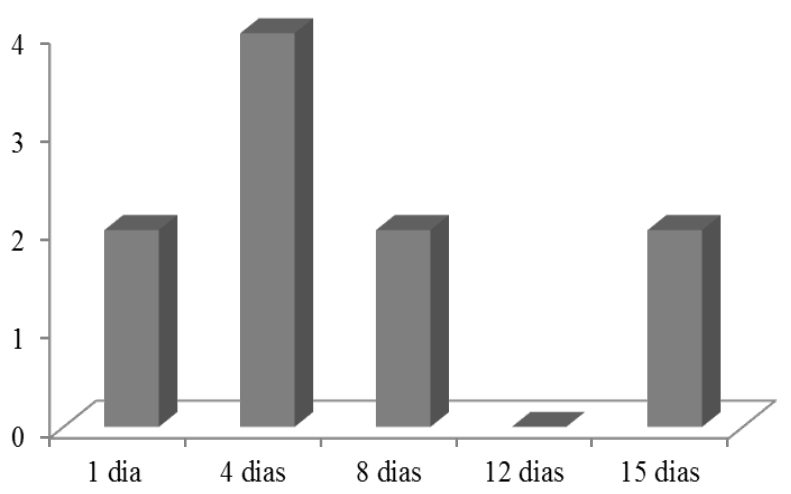

Figura 3: Número de rebrota de $C$. spectabilis após aplicação de 2,4-D na dose duplicada.

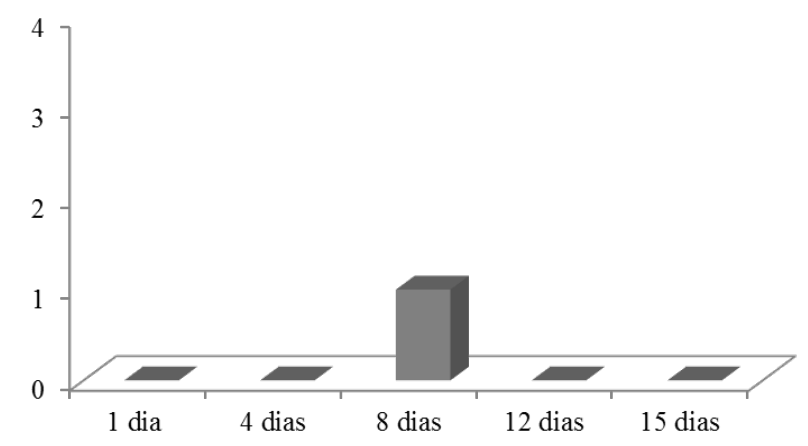

Os diferentes períodos de carência bem como as diferentes doses analisadas influenciaram o índice de clorofila (Tabela 1 e Figura 4). O período de carência recomendado (15 dias) foi aquele que expressou maior índice de clorofila em relação aos demais (Tabela 2), assim como a dose recomendada.

Tabela 1: Índice de clorofila das folhas de soja submetidas a diferentes intervalos de semeadura e aplicação de 2,4-D

\begin{tabular}{c|c|}
\hline Período de carência (dias) & Índice de clorofila \\
\hline 1 & $28,11 \mathrm{~b}$ \\
\hline 4 & $28,43 \mathrm{~b}$ \\
\hline 8 & $27,88 \mathrm{~b}$ \\
\hline 12 & $28,25 \mathrm{~b}$ \\
\hline 15 & $33,80 \mathrm{a}$ \\
\hline $\mathrm{CV}(\%)$ & 7 \\
\hline
\end{tabular}

Médias seguidas pela mesma letra não diferem significativamente entre si pelo teste Tukey a 5\% de probabilidade.

$\mathrm{CV}=$ coeficiente de variação.

Figura 4: Índice de clorofila em plantas de soja expostas a diferentes doses de 2,4-D em pré emergência. Significativo ao nível de $5 \%$ de probabilidade.

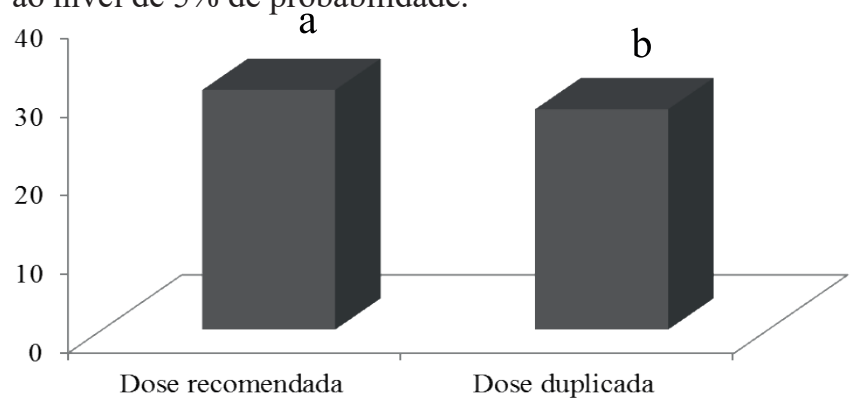

Médias seguidas pela mesma letra não diferem significativamente entre si pelo teste Tukey a 5\% de probabilidade.

Com relação à massa fresca, os resultados obtidos não foram significativos para doses, períodos de carência e a interação entre eles $(\mathrm{CV}=41,16 \%)$. Contudo, para o parâmetro massa seca, observou-se diferença significativa entre as doses testadas, sendo que na dose recomendada o valor médio de massa seca foi $0,36 \mathrm{~g}$ e na dose duplicada $0,23 \mathrm{~g}$.

Além da redução no comprimento da raiz e parte aérea, sintomas de fitotoxidade como raízes anormais e deformadas e epinastia das folhas e caule, foram observados em todos os períodos de carência do tratamento com dose duplicada, sendo mais frequente nos intervalos de quatro e oito dias.

O comprimento do sistema radicular foi afetado tanto pelas doses quanto pelos períodos de carência avaliados. A dose duplicada de 2,4-D interferiu negativamente no desenvolvimento das raízes, cujo comprimento médio diferiu significativamente $(\mathrm{p}<0,05)$ do tratamento com aplicação da dose recomendada (Tabela 2 ). 
Tabela 2: Comprimento da parte aérea e raiz $(\mathrm{cm})$ de plantas de soja submetidas a diferentes doses de 2,4-D na pré-emergência.

\begin{tabular}{l|c|c}
\hline & Parte aérea & Raiz \\
\hline Dose recomendada & $20,58 \mathrm{a}$ & $21,70 \mathrm{a}$ \\
\hline Dose duplicada & $13,68 \mathrm{~b}$ & $10,08 \mathrm{~b}$ \\
\hline CV $(\%)$ & 13,45 & 11,22 \\
\hline
\end{tabular}

Significativo ao nível de 5\% de probabilidade.

$\mathrm{CV}=$ coeficiente de variação

Os períodos de carência de um, quatro e oito dias não variaram significativamente entre si (Tabela 3 ) e influenciaram de maneira negativa o comprimento da raiz, no entanto, diferiram dos períodos de 12 e 15 dias, os quais promoveram maior crescimento médio das raízes (Tabela 3 ).

Tabela 3: Comprimento de raiz $(\mathrm{cm})$ de plantas de soja avaliadas após diferentes intervalos de semeadura e aplicação do 2,4-D

\begin{tabular}{c|c}
\hline Período de carência (dias) & $\begin{array}{c}\text { Comprimento de raiz } \\
\text { (cm) }\end{array}$ \\
\hline 1 & $13,54 \mathrm{~b}$ \\
\hline 4 & $14,44 \mathrm{~b}$ \\
\hline 8 & $14,60 \mathrm{~b}$ \\
\hline 12 & $18,40 \mathrm{a}$ \\
\hline 15 & $18,46 \mathrm{a}$ \\
\hline $\mathrm{CV}(\%)$ & 11,22 \\
\hline
\end{tabular}

Médias seguidas pela mesma letra não diferem significativamente entre si pelo teste Tukey a $5 \%$ de probabilidade.

$\mathrm{CV}=$ coeficiente de variação

O comprimento da parte aérea foi influenciado pelas doses conforme observado na Tabela 2, mas não pelos períodos de carência. O maior comprimento, a exemplo do observado para o crescimento de raiz, foi verificado nas plantas expostas à dose recomendada de 2,4-D, enquanto o menor comprimento da parte aérea foi observado ao se aplicar a dose duplicada do produto.

\section{Discussão}

O efeito residual do 2,4-D sobre o desenvolvimento inicial da soja foi observado em todos os tratamentos com diferentes doses e tempo carência, confirmando as recomendações de bula do produto que indicam semeadura da soja, no mínimo 15 após a aplicação. A atividade residual deste herbicida tem sido verificada nas primeiras semanas após sua aplicação conforme relatam Silva et al. (2007) e Silva et al. (2011).

Valente e Cavazzana (2000) também observaram influência negativa do herbicida 2,4-D na emergência de plantas, constatando redução no número de plantas de soja por metro linear após aumento da dose de aplicação de 2,4$\mathrm{D}$ em diferentes períodos de carência avaliados. De maneira similar, Silva et al. (2011) verificaram baixo percentual de emergência de plântulas de soja quando aplicado 2,4-D na dosagem $1.005 \mathrm{~g}$ e.a. ha $^{-1}$ no período de 0 dias após da semeadura. No entanto, a aplicação desta mesma dosagem aos
5, 7 e 10 dias após a semeadura não diferiram da testemunha, mas apresentaram redução significativa na porcentagem de emergência em comparação aos demais tratamentos.

Ao avaliarem o efeito residual do herbicida flumioxazin sobre a emergência de plantas daninhas em solos com diferentes texturas, Jaremtchuk et al. (2009) detectaram variação na atividade residual do herbicida no controle da emergência em relação à textura do solo, do período entre aplicação e semeadura e da dosagem utilizada. Este último foi perceptível neste trabalho ao utilizar-se o 2,4-D em pré-emergência da soja.

Os sintomas de fitointoxicação observados também foram relatados por Silva et al. (2011) em plantas de soja e Constatin et al. (2007) em trabalho simulando deriva de 2,4D na cultura do algodoeiro e podem ser explicados pela ação do 2,4-D, quando aplicado em pós-emergência, o qual pode ocasionar danos no câmbio resultando na inibição da elongação do caule (GUEVARA, 1998).

$\mathrm{O}$ índice de clorofila nas folhas é proporcional à quantidade de nitrogênio que ela absorve, e a capacidade de metabolizar o nitrogênio está diretamente relacionada à sua sanidade (SEDIYAMA; SILVA; BARÉM, 2015). Portanto, estes resultados sugerem que o uso do herbicida 2,4-D de maneira diferente da recomendada influencia diretamente a sanidade e a fisiologia da planta.

A massa seca foi inferior nas plantas submetidas à dose duplicada, no entanto, as diferentes doses testadas não foram significativas, diferente do observado no trabalho de Silva et al. (2011) os quais verificaram os menores valores para biomassa quando aplicadas as dosagens mais elevadas aos cinco e 10 dias antes a semeadura.

Yamashita, Borges e Carvalho (2010) não observaram emissão de radícula em sementes de corda-de-viola submetidas às doses de dois, quatro e seis $\mathrm{L} / \mathrm{ha}^{-1}$ de 2,4-D. Neste trabalho, entretanto observou-se emissão de radícula, contudo, tanto o comprimento da parte aérea, quanto da raiz, foram afetados pelas doses, sendo o sistema radicular também influenciado pelos períodos de carência. Varela apud Brighenti et al., (2002) relataram a dilatação do hipocótilo e a diminuição do crescimento de raízes secundárias com resposta diferencial para algumas cultivares de soja.

Para o comprimento da parte aérea, houve efeito significativo das doses (Tabela 2) assim como observado por Silva et al. (2011) os quais também relataram, para todos os períodos de aplicação, redução da altura em relação à testemunha. $\mathrm{O}$ aumento da dose promoveu a redução da altura das plantas de soja em todos os períodos de aplicação, mas essa redução foi significativa apenas no período de sete dias antes da semeadura.

Vários fatores induzem o agricultor a aplicar doses superiores às recomendadas ou encurtar o período de carência exigido, a fim de buscar um controle mais eficaz da população de plantas daninhas. Por meio da aplicação manual, equipamentos auto propelidos ou aviões, é comum observar no campo áreas de superdose, as quais recebem o produto duas vezes. Este problema dificilmente pode ser eliminado, entretanto, pode ser amenizadas por meio da adoção de boas práticas de aplicação, tecnologias como a navegação por GPS ou controle de tráfego agrícola nas áreas de lavoura.

\section{Conclusão}


O uso do 2,4-D em desacordo com as recomendações de dosagem e período de carência afeta parâmetros de crescimento e desenvolvimento em plantas de soja.

\section{Referências}

ADAMA BRASIL. Manejo de plantas daninhas. Disponível em: <https://www.adama.com/brasil/pt/manejode-plantas-daninhas/manejo-caracteristicas-e benefícios $>$. Acesso em: out. 2017.

ALVES, L. W. R. Efeito da aplicação de doses reduzidas dos herbicidas glyphosate e oxyfluorfen, simulando deriva sobre a cultura do milho (Zea mays L.). 1999. 80 f. Dissertação (Mestrado em Agronomia) - Universidade Federal de Lavras, Lavras, 1999.

BRIGHENTI, A. M. et al. Tolerância de genótipos de soja aos herbicidas trifluralin e imazaquin. Planta Daninha, v. 20 , n. 1, p. 63-69, 2002.

BRIDGES, D. C. Mechanism of action of inhibitors of amino acid biosynthesis. In: HERBICIDE action course: an intensive course on the activity, selectivity, behavior and fate of herbicides in plants and soil. West Lafayette: Purdue University, 2003. p. 344-365.

CONSTANTIN, J. et al. Efeito de subdoses de 2,4-D na produtividade do algodão e suscetibilidade da cultura em função de seu estádio de desenvolvimento. Engenharia Agrícola, v. 27, n. esp. p. 24-29, 2007.

FERREIRA, D. F. Sisvar: a computer statistical analysis system. Ciência e Agrotecnologia, v. 35, n. 6, p. 1039$1042,2011$.

GAZZIERO, D. L. P.; NEUMAIER. N. Sintomas e diagnose de fitotoxidade de herbicidas na cultura da soja. Londrina PR. EMBRAPA, 56 p.1985.

GUEVARA, G. Efecto del 2,4-D sobre el algodón. Saenz Peña: Instituto Nacional de Tecnologia Agropecuária. 1998 12 p. (Boletim Técnico, 12).

JAREMTCHUK, C. C. et al. Efeito residual de flumioxazin sobre a emergência de plantas daninhas em solos de texturas distintas. Planta Daninha, v. 27, n. 1, p. 191-196, 2009

MAGALHÃES, P. C.; DURÃES, F. O. M.; DA SILVA, J. B. Efeito da deriva de herbicidas na fonte de fotoassimilados em sorgo. In: CONGRESSO BRASILEIRO DE FISIOLOGIA VEGETAL, 6., Belém, 1997. Anais... Belém, PA, 1997. p. 227.

PURÍSSIMO, C. Classificação de herbicidas quanto ao mecanismo de ação. In: SEMINÁRIO SOBRE SISTEMA PLANTIO DIRETO NA UFV, 2, Viçosa, 1999. Anais... Viçosa, 1999. p.73-110.

RODRIGUES, B. N.; ALMEIDA, F. S. Guia de herbicidas. 5. ed. Londrina: Grarfmake, 2011.
SEDIYAMA, T.; SILVA, F.; BORÉM, A. Soja do plantio a colheita. Viçosa: UFV, 2015.

SILVA, A. A.; SILVA, J. F. Tópicos em manejo integrado de plantas daninhas. Viçosa: Universidade Federal de Viçosa, 2007.

SILVA, L. M. F. Atividade residual de 2,4-D sobre a emergência de soja em solos com texturas distintas. Revista Brasileira de Herbicidas, v. 10, n. 1, p. 29-36, 2011.

VALENTE, T. O.; CAVAZZANA, M. A. Efeito residual do chlorimuron-ethyl aplicado em mistura com glyphosate na dessecação de plantas daninhas. Revista Brasileira de Herbicidas, v. 1, n. 2, p. 173-178, 2000.

VARELA, R.; DE LA CRUZ, R. Effecto de algunal dinitroanilinas sobre la nodulacion de la soya (Glycine max (L.) Merr.). Revista do Instituto Colombiano de Agropecuária, v. 19, n. 1, p. 17-23, 1984.

YAMASHITA, M. O.; BORGES, H. R.; CARVALHO, C. M. Efeito de três herbicidas na germinação de corda-deviola (ipomoea quamoclit) em substrato umedecido. Revista

Científica Eletrônica de Agronomia, Garça, v. 17, n. 1, p. $17-22,2010$. 